\title{
Diversification Strategy and Sustainable Development of Mining Companies in the Eurasian Mining Region
}

\author{
Dmytro Voronets ${ }^{1}$, Olga Garafonova ${ }^{1,2, *}$ Irina Verezomska $^{3}$, and Oksana Oliinyk ${ }^{4}$ \\ ${ }^{1}$ Management Department, Economics and Management Faculty, Kyiv National Economic \\ University, Kyiv, 03057, Ukraine \\ 2 Management Department, Economics and Management Faculty, Kyiv National Economic \\ University, Kyiv, 03057, Ukraine \\ ${ }^{3}$ Kyiv National University of Culture and Arts, Kyiv, Ukraine, 01601, Kyiv, Evgena Konovalca, 36 \\ ${ }^{4}$ Private Higher Educational Institution "Kyiv University of Culture", Kyiv, Ukraine, 01601, Kyiv, \\ Evgena Konovalca, 36
}

\begin{abstract}
The aim of this study is to examine the relationship between diversification strategies implementation and sustainable development goals of mining companies of Eurasian mining region in modern conditions. Today Eurasia is very rich region with minerals-driven sustainable development goals and challenges. In this case it is important to improve strategies of mining companies of Eurasia and to listen to the biggest companies` experience. Diversification strategy is one of the most progressive way to develop mining companies wherein Global Sustainable Development Goals must be considered. Diversification of the enterprise could be realized in such ways: as the extension of its business activities to new areas or as the capital diversification - diversification of assets in company's investment portfolio. Over the past two years, from 2017 to the beginning of 2019, the number of diversified companies in the TOP 30 Mining companies of the world, according to the PWC consulting company and the Mining[dot]com resource, increased from 8 to 13. Thus, it is important to study the possibilities and features of implementing diversification strategies for mining enterprises of Eurasian mining region. In research it is presented the algorithm of the model, compiled on the basis of the development as applied to solving the problem of diversification of a mining enterprise.
\end{abstract}

\section{Introduction}

In spite of the strong operating performance, both investors and consumers seem to be down on the brand of mining. They question whether the industry can responsibly create sustainable value for all stakeholders. Discrete events, such as safety or environmental incidents, have contributed to these challenges.

\footnotetext{
${ }^{*}$ Corresponding author: ogarafonova@ukr.net
} 
While they appreciate the efforts to improve operations and engineer superior results, it is clear that investors and other stakeholders are concerned that the industry is lagging when it comes to several factors that have not been a traditional focus of the mining industry. These include dealing with emissions, investing in differentiating technology and digitalization, engaging more proactively with consumers and building brand. Looking ahead to the rest of 2019 and beyond, we see a continuation of the strong operating performances, and pockets of progress in these contemporary factors. But we don't see any signs of a quantum shift in priorities that will allow the industry as a collective to keep pace with changes delivered in other sectors. Without such a shift, we expect the growing awareness gap between the brand of mining and the benefits of mining to continue to widen.

To restore faith in 'brand mining', leading miners need to prove they are keeping up with the pace of change. As an industry, this means transforming their reputation as efficient 'converters of dirt' to prominent builders of both economic and societal capital. Prioritizing green and customer-centric strategies, enabled by technology, will help earn the trust of stakeholders and enable miners to create sustainable value into the future. [1]

The mining industry impacts all 17 of the Sustainable Development Goals to varying degrees through mining itself, social investments, taxes and investment of public revenues.

Mining has the most direct impact on six goals:

- SDG15 (Ecosystem and Biodiversity Protection)

- $\quad$ SDG13 (Climate Action)

- $\quad$ SDG9 (Infrastructure, Innovation, and Industrialization)

- $\quad$ SDG8 (Employment and Economic Growth)

- $\quad$ SDG7 (Energy Access and Sustainability)

- $\quad$ SDG6 (Clean Water and Sanitation). [2]

\section{Results}

Eurasia has recovered from the recession of the 1990s and is integrating into the world economy-primarily through its abundant natural resources. The resource-rich countries of Eurasia have benefited from global economic growth. After all, Eurasia has more than onethird of the world's reserves of oil, gas, bauxite, and gold, and prices for these commodities have surged since 2000, boosting resource-related revenues. The other countries of Eurasia have also benefitted from the resource abundance of their neighbors through trade, capital flows, and remittances. Governments would do well to review strategies that rely on interventions to stimulate specific sectors or activities. Instead, it would be far more effective if Eurasian countries focused more on diversifying their national asset portfolios - that is, to ensure better balance between natural resources, physical and human capital, and economic institutions. $[3,4]$

Considered as a growth strategy the rationale of diversification, is for a company to explore new business areas that promise greater profitability. For a company to diversify, it needs to enter/expand in new markets or product lines which are related or/and unrelated to its existing businesses. [5] Diversification generally requires new skills, new techniques, and new facilities. As a result, it almost invariably leads to physical and organizational changes in the structure of the business which represent a distinct break with past business experience.[6]

The crux of the issue around diversification is one of minerals-driven sustainable development. The principal premise here is that while minerals are in themselves a depleting, non-renewable resource, the mistake is often made of considering minerals industries to be unsustainable. Without question, in themselves mines, and hence their 
industries, have defined lives. However, mining is a robust pioneering primary industry in difficult arenas such as deep rural areas and zones of high conflict. Typically, mining provides for the development of infrastructure and economic activity where few other sectors could or would venture. In this sense it has the propensity to spawn or catalyze the development of direct and indirect secondary and tertiary sectors that could, properly planned and managed, be sustainable.

Sustainability within the minerals sector depends entirely on the ability of governments' to:

a) plan their minerals economies in such a way as to maximize the development of mining-related secondary and tertiary sectors during the currency of mining operations;

b) encourage the development of non-mining related activities around mining service industries and mining infrastructure

c) in so doing, to diversify the use of mining infrastructure while it is being subsidized by mining sectors to the extent that the closure of the mines for which the infrastructure was developed does not cause its collapse;

d) actively encourage non-mining investment in mining regions to reduce the dependency of local, regional and indeed national economies on minerals and to simultaneously reduce the dependence on local infrastructures on mines.

The reality of the matter is however that most governments in developing economies are under-resourced for various reasons ranging from the lack of a firm tax base as a result of an under-performing or under-developed economy to the lack of economic planning experience and a dearth of well qualified economic planners. In this sense responsibility for achieving these objectives lies not only with the governments themselves and those intergovernmental and development organizations that assist them in their planning efforts, but also strongly with a responsible private sector. [7]

Economic diversification simply will not happen without an active planning process involving government, labor and private sector interests. In this sense, the planning for diversification goes far beyond the commonly accepted notions of:

1. Diversifying the use of mining infrastructure;

2. Promoting downstream and vertically-integrated minerals-based industries;

3. Planning for post-mining sustainable use of this infrastructure and well-being of the community;

4. The provision of investment incentives.

Diversification of the economy can take many indirect forms founded on the direct use of mining rents to:

1. Maximize the rents from mineral industries through constructive equity participation rather than relying purely on returns from royalties and taxation revenues;

2. Actively diversify the minerals sector itself;

3. Build a large and available mining skills base in order to facilitate the rapid development of mineral-based economic alternatives through investment in and support of appropriate training and educational facilities and programs;

4. Invest in infrastructure that will enable the development of otherwise marginal mineral deposits;

5. Invest in existing mining-related infrastructure to diversify the economic use of this infrastructure during the currency of mining operations;

6. Invest in non-mining related infrastructural and social development programs which will in turn generate immediate and sustainable economic activities not necessarily directly related to or dependent on mining;

7. Plan for and stabilize government spending though the judicious use of foreign exchange-based investment instruments to act as a buffer to volatile commodities markets; 
8. Exert strict financial discipline to ensure adherence to these government spending programs;

9. Employ all available fiscal instruments to attract investment rather than resorting to grant based incentives; and

10. Constantly review mining and investment codes in close consultation with potential investors in order to encourage investment by demonstrating a willingness to co-operate with investors. [7]

The Table 1 [8] shows the ranking of mining companies as of April 2017 with division into mono-enterprises and diversified.

Table 1. Top 30 Mining Companies Market Capitalization USD Billions April 2017.

\begin{tabular}{|c|c|c|c|}
\hline No & Company & Operations & Market cap - USD billions \\
\hline 1 & BHP Billiton & Diversified & 90.67 \\
\hline 2 & Rio Tinto & Diversified & 74.04 \\
\hline 3 & Glencore & Diversified & 55.98 \\
\hline 4 & China Shenhua Energy & Coal & 54.96 \\
\hline 5 & Vale & Steel Raw Materials & 48.31 \\
\hline 6 & Coal India & Coal & 28.18 \\
\hline 7 & Southern Copper & Base Metals & 28.04 \\
\hline 8 & Norilsk Nickel & Base Metals & 25.30 \\
\hline 9 & Barrick Gold & Precious Metals & 22.67 \\
\hline 10 & Anglo American & Diversified & 21.28 \\
\hline 11 & Freeport-McMoRan & Base Metals & 19.21 \\
\hline 12 & Hindustan Zinc & Base Metals & 18.95 \\
\hline 13 & Newmont Mining & Precious Metals & 18.03 \\
\hline 14 & Polyus & Precious Metals & 17.34 \\
\hline 15 & Fortescue Metals Group & Iron Ore & 14.68 \\
\hline 16 & Potash Corp & Potash & 14.19 \\
\hline 17 & Fresnillo & Precious Metals & 14.06 \\
\hline 18 & Newcrest Mining & Precious Metals & 13.21 \\
\hline 19 & Teck Resources & Diversified & 12.95 \\
\hline 20 & Ma'aden & Diversified & 12.71 \\
\hline 21 & Goldcorp & Precious Metals & 12.58 \\
\hline 22 & Vedanta & Diversified & 12.08 \\
\hline 23 & Alrosa & Diamond & 12.08 \\
\hline 24 & Franco Nevada & Precious Metals & 11.69 \\
\hline 25 & South32 & Diversified & 11.30 \\
\hline 26 & China Coal Energy & Coal & 10.40 \\
\hline 27 & Antofagasta & Base Metals & 10.28 \\
\hline 28 & Zijin Mining & Precious Metals & 10.22 \\
\hline 29 & PeĐoles & Precious Metals & 10.21 \\
\hline 30 & Mosaic & Potash & 10.07 \\
\hline
\end{tabular}

Over the past two years, from 2017 to the beginning of 2019, the number of diversified companies in the TOP 30 Mining companies of the world, according to the PWC consulting company [1] and the Mining[dot]com resource [9,10], increased from 8 to 13 . Based on the 
data in the Table 1 and data from PwC's 16th annual review of global trends in the mining industry [8] we can conclude that diversified industries are much more efficient in their core business than enterprises focused on one type of minerals.

One of the important and successful levers for managing mining in a market economy is its diversification. In a more general case, two procedures are distinguished:

- diversification of the enterprise, as the extension of its business activities to new areas (expanding the range of products or types of high services);

- capital diversification - allocation of money invested in the economy (for example, part of the profit from the main activity) in order to reduce risk or generate additional income.

Within the designated framework, the following types of diversification of mining enterprises can be distinguished:

1) the use (utilization) of the mineral product mined or obtained during the primary processing of ore mass (concentration);

2) integrated development of deposits, other than those identified as minerals for the extraction of minerals, minerals and mining;

3 ) the integrated development of mineral resources in the fields, with the exception of the two previous technologies, ensuring the production of both typical and non-traditional for the mining production of additional functions that allow you to create whole or part of the infrastructure and technological tools created to extract the main or additional minerals.

Common to the selected options is that in all cases, diversification is carried out on the basis of resources (minerals, mining, main production waste, etc.) that the enterprise has. The peculiarity of the first of these varieties of diversification is that the company invests insignificant, sometimes negligible capital on the formation of a line for the production of new (in addition to the main) products. The thing is that when extracting the main mineral resource, an enterprise inevitably extracts large volumes of various rocks from the subsoil, for example, during the excavation of underground mine workings or during overburden operations in quarries. It is known that rocks in their original or processed form are always in demand in the market. If the volumes of incidentally mined rocks are small compared with the volumes of extraction of the main mineral (ore), then the market value and selling price of them are formed only from the direct costs of their transportation and processing. In the case when the volumes of simultaneously mined and of interest on the market rocks are comparable with the volumes of extracted main minerals, the reserves of these rocks within the mine or quarry fields are calculated and approved as minerals in accordance with existing requirements. It also helps to reduce the cost of the main products of the enterprise and increase its competitiveness in the market. With diversification, the viability of the enterprise increases significantly, and the degree of its increase depends on the amount of additional income received by the company from the sale of "non-core" products. The enterprise as a result of the implementation of technological mining processes for the main project receives raw or salable ore and simultaneously various so-called "empty" rocks. However, the market price of products is greater, the higher the degree of processing of raw materials. Following this well-known truth, mining enterprises subject the mined rocks to various processing, the depth of which depends on market demand, technical capabilities and economic feasibility.

The second type of diversification of mining enterprises differs from the first in that, along with the disposal of incidentally mined rocks, they carry out specialized mining of certain types of mineral raw materials, which are absent in the bulk extracted from the subsoil, but are located directly in the mine field of the enterprise or in the zone of its economic influence. This is achieved on the basis of a more complete use of the enterprise infrastructure and, if required, with a certain qualitative and quantitative development. This kind of diversification of a mining enterprise is based on a deeper study of the market and is 
more responsive to demand and prices for various mineral raw materials, but requires the enterprise to have significant financial and production capabilities, and most importantly the presence in the bowels of the relevant reserves of previously noted raw materials.

The first two varieties of diversification of mining enterprises considered in all aspects are closely related to the initial project for the extraction and processing of the main oremineral raw materials. True, at the final stages, the technological lines for the processing of primary and secondary raw materials can vary significantly.

\section{Discussion}

The task of diversification includes many aspects of the enterprise that change over time and have varying degrees of uncertainty. The solution to this problem is preceded by the development of an economic-mathematical model of the rational distribution of capital over time with the diversification of mining. This model allows to formulate a diversification strategy for the enterprise and choose the most effective of them from an economic point of view. The quality assessment of various directions of diversification of production in this case can be performed using the indicator of internal rate of return (GNI). However, taking into account the drawback of this indicator, which consists in the possibility of the existence of multiple roots for solving the equation, the model also uses additional criteria: net present value (NPV) and profitability index (IPR). The simultaneous use of these criteria for evaluating the effectiveness of the selected option allows you to take into account the disadvantages of each of them. The algorithm of the model, compiled on the basis of the development as applied to solving the problem of diversification of a mining enterprise:

1. At the first stage, the characteristics of various projects are compiled. They also introduce restrictions on investments, marginal rate of income, and the life of production;

2. For each project, possible cash flows are evaluated: positive, negative and net;

3. Establish the number of projects for further consideration;

4. For each project, the number of alternatives is determined. If they are, then conduct a marginal analysis;

5. Select the best projects from among alternative ones;

6. Form the number of projects for economic evaluation (non-alternative projects + the best of the alternative according to the results of marginal analysis);

7. The remaining projects are evaluated according to the GNI criterion (internal rate of return). At this stage, it is assumed that the start dates of the analyzed industries coincide;

8. According to the GNI indicator, the number of projects included in the enterprise development strategy is estimated. In this case, take into account the limitation of capital available to the enterprise for the implementation of projects;

9. Form an enterprise development strategy. Take into account the effectiveness of each of the projects, equity, as well as the possibility of reinvestment of income. There are two main development strategies;

10. According to the first strategy, all projects are ranked according to the GNI indicator. The sequence of input projects is determined, starting from the one that has the maximum value of GNI;

11. Allocate the second development strategy. Here, all projects are ranked by the deadline for the start of construction. On this basis, projects are ranked, starting with one that is characterized by a minimum deadline for the start of construction, taking into account the total possible amount of capital;

12. Assess the totality of all attracted projects according to the criterion of net present value (NPV). The assessment is carried out sequentially as subsequent projects are involved 
in the strategy. Attracting a project is considered justified if it does not lead to a decrease in the NPV of the totality of previous projects;

13. Choose the most effective strategy for the development of the enterprise on the basis of comparing them according to the criterion of profitability index (IPR), determined by the ratio of positive and negative cash flows taking into account the time factor.

The adopted strategy determines both the most appropriate timing for the commissioning of each project and the appropriate distribution of investments over time. The two forms of diversification considered are ubiquitous in mining enterprises. And the matter is not only in the unequivocal profitability of this event, but also in the fact that enterprises radically and scale solve another problem - the environmental one. Mining and processing (especially in open pit mining) have a very negative impact on the environment. Moreover, the factor that plays the largest role in this process is the overburden rock stored in dumps.

\section{Conclusion}

The larger volumes of waste rock will be used as minerals, i.e. as raw materials for the preparation of products, the ecology of the mining enterprise will improve to a greater extent, and, as was shown earlier, the more profit it will receive. At the same time, it should be remembered that any waste is products for which application has not yet been found. It seems that most mining and processing enterprises remember this, expand the assortment of products from overburden rocks and successfully market it, competing with enterprises that are traditional suppliers of these products. There is hope that in the future the entire volume of waste in mining enterprises will be disposed of. In this regard, the preconditions for the restructuring of the raw material base of such a powerful industry as the building materials industry are being formed in the regions. The main idea is to completely abandon countless small quarries and quarries for the extraction of raw materials for enterprises producing construction materials in the entire country in large mining regions, and to receive them only from mining and processing enterprises, which will be much cheaper, better for quality and dramatically improve the environmental situation.

\section{References}

1. Mine 2019. Resourcing the future. URL: https://www.pwc.com/gx/en/energy-utilitiesmining/publications/pdf/mine-report-2019.pdf

2. M.A. Klimovich, Economics and Innovation Management, 1, 18-25 (2019) DOI: 10.26730/2587-5574-2019-1-18-25

3. Diversified Development: Making the Most of Natural Resources in Eurasia (International Bank for Reconstruction and Development, 2014)

4. N.V. Kudrevatykh, A.A. Galler, Economics and Innovation Management, 1, 45-54 (2019) DOI: 10.26730/2587-5574-2019-1-45-54

5. İbrahim Anıla, IhsanYiğitb. Procedia - Social and Behavioral Sciences, 24, 214941509 (2011)

6. S.A. Zhironkin, Ugol', 4, 29-31 (2001)

7. M. Cehlár, P. Rybár, J. Mihók, J. Engel, Journal of Mining and Geotechnical Engineering, 1:4, 4-23 (2019). DOI: 10.26730/2618-7434-2019-1-04-23

8. S.M. Miliy, M.A. Rozhenko, K.A. Prokopenko, G.I. Korotkova, Journal of Mining and Geotechnical Engineering, 2:5, 4-18 (2019). DOI: 10.26730/2618-7434-2019-2-04-18 
9. TOP 50 Mining Companies. URL: https://datawrapper.dwcdn.net/geN1p/4/

10. Value of top 50 mining companies surge $\$ 140$ billion in 2017 . URL: https://www.mining.com/value-top-50-mining-companies-surge-140-billion-2017/ 